\title{
Sustaining Solutions in Undergraduate STEM Education
}

\author{
By Ellene Tratras Contis ${ }^{*} \&$ Batoul Abdallah ${ }^{ \pm}$
}

\begin{abstract}
Science, Technology, Engineering and Mathematics (STEM) programs that attract and sustain student interest feature learning that is experiential, investigative, hands-on, personally significant to both students and faculty, connected to other inquiries, and suggestive of practical application to students' lives. Such learning flourishes in a community in which faculty are committed equally to teaching, to maintaining their own intellectual vitality, and to partnering with students in learning, and in which institutional support for such a community exists. The Creative Scientific Inquiry Experience (CSIE) Program at Eastern Michigan University (EMU) is involved in retaining and increasing the number of STEM graduates by including faculty professional development, student connectedness to the sciences and mathematics through academic service-learning, and curricular reform. In this conference paper we report on the success of the CSIE program, including course development, student engagement, student success, especially among underserved students, and sustainability. This work is important because it offers insight into the development, sustainability, and scalability into faculty-driven STEM education reform spanning 15 years.
\end{abstract}

Keywords: STEM education, retention strategies, undergraduate STEM, majors/non-majors

\section{Introduction}

STEM education currently faces significant challenges related to retention and achievement, especially among undergraduate students. Approximately $20 \%$ and $28 \%$ of freshmen in 2-year and 4-year institutions, respectively, declare a major in a STEM field. However, 69\% and 48\% of those students leave STEM before earning a college degree (Meyers and Jones 1993). Most students who declare a STEM major leave STEM fields, citing poor student performance, unengaging coursework and poor teaching by STEM faculty. Another crisis facing STEM is the workforce shortage, as constant innovation drives demand for highly skilled professionals. At the current rate, an estimated one million more jobs will be necessary to meet that demand over the next decade, indicating that the number of graduates of STEM degrees must increase by 34\% (Xue and Larson 2015). It is important to note that there is significant variation and even a surplus among workforce demands related to: discipline, education level, sector (government, academia, private), and geographical location (King et al. 2015, Mailloux and Grimaila 2018).

"Professor \& Creative Scientific Inquiry Experience (CSIE) Director, Eastern Michigan University, USA.

${ }^{ \pm}$CSIE Program Manager, Eastern Michigan University, USA. 
To address concerns of STEM attrition and workforce shortages, significant investment was made into post-secondary educational programming with an overall goal to recruit, retain, and increase achievement of students in STEM fields. These reforms include the implementation of high impact practices such as the creation of faculty and student learning communities, course-based and summer undergraduate research, mentoring, academic support, among others. Many of these reforms have worked at recruitment, retention, and increasing student engagement and achievement in STEM fields (Caniglia and Tratras Contis 2013, Estrada et al. 2016, Kendricks et al. 2019, Theobald et al. 2020, Tratras Contis 2014). Specifically, course-based undergraduate research experiences (CURE) are among the strongest best practices for increased student engagement. CUREs can be designed to be scaffolded throughout students' academic careers to include research, career development, and internships (Ashcroft et al. 2020). CURE's are highly effective at building a strong STEM identify, increasing students' confidence in science and in research aptitude, and building self-efficacy, particularly among underserved students (Ashcroft et al. 2020, Syed et al. 2019). Taken together, undergraduate research experiences strengthen career pipelines as students acquire knowledge and skills necessary for STEM careers. Despite the successes of many best practices, including undergraduate research, many challenges remain, including closing the achievement gap, inadequate resources for implementation, institutional and faculty-related barriers, and widespread scaling of successful best practices in STEM education.

Here, we report on the Creative Science Inquiry Experience (CSIE) at Eastern Michigan University (EMU). EMU is a state university of about 20,000 undergraduate and graduate students and located in the southeast corner of Michigan. CSIE is an undergraduate seminar STEM program that connects students with faculty and community projects with an integrated science curriculum. The impacts on STEM students, faculty, curriculum, and community involvement will be reported, as well as, the benchmarks used to measure the success of our students. Specifically, we discuss our successes with faculty professional development and course development, the creation of an inclusive STEM culture, and its subsequent success on student achievement, especially among underserved students. We also discuss our efforts on sustainability and possibilities for scalability into other institutions.

\section{Methodology}

Many universities experience several challenges and barriers to STEM learning. EMU experienced many, including the following: siloed STEM departments; lower STEM retention, lower next-in-progression enrollment (students did not continue in their STEM coursework); student interest waned after first term due to amount and difficulty of coursework; no mentoring/advising, and no connections to faculty; lower diverse STEM population, especially among underserved groups. 
We are fortunate to have opportunities at EMU that include EMU faculty who are really interested in helping our students get a solid STEM education. We have a focus on undergraduate research and many of our faculty have students who work in the lab, alongside graduate students. Our students present at regional/ national conferences and coauthor manuscripts for publication. Our Faculty Development Center is strong and supportive in providing professional development for out faculty and is run by a biology faculty. Our location in southeast Michigan positions us for connections and partnerships to our local and large STEM industries of which auto manufacturing is key. Our University leaders encourage faculty-driven change. We have a diverse student body - according to US World \& News report, EMU is the most diverse university in the Midwest United States.

Therefore, the elements to a solution for us included hands-on (experiential) learning strategies where students and faculty collaborate with community partners to solve local issues. Faculty interdisciplinary teams were formed to develop and implement interdisciplinary seminars. We wanted culturally relevant connections to the community. We wanted to develop a sustainable program to increase community awareness with faculty and students.

\section{Program Description}

The CSIE program at Eastern Michigan University (Caniglia and Tratras Contis 2013) has created interventions that support high academic standards through increased student success, supporting student academic career development and experiential learning, provide faculty professional development, and institutionalization of key project components. The CSIE model was developed using Academic Service-Learning (ASL) and experiential learning approaches. ASL is an innovative teaching and learning practice that connects meaningful, community-based projects to course content and instruction with the intent of enhanced student and civic learning. Experiential learning is a complex active learning strategy that immerses students in a particular setting and encourages reflection for conceptual and skill development. The CSIE model represents a powerful combination of both strategies by encouraging interdisciplinarity and collaboration between STEM faculty of different disciplines through course development workshops. Faculty focus on identifying courses for integration, common themes, and community and/or industry partners for learning experiences. CSIE is currently being adopted at the institutional level to be sustained beyond grant project completion. The methods used by CSIE to fulfill and institutionalize project objectives are: experiential learning course development, course regularization, course-tagging for transcript recognition of student experience, completion of a STEM student workspace, developing and cultivating community partnerships, faculty professional development, faculty-student mentoring, career exploration, advising and long-term planning and campus and community outreach through informal student learning events.

Creative Science Inquiry Experience is a STEM program first funded by the US National Science Foundation in 2005, and then by the US Department of 
Education in 2013 that specializes in creating learning experiences to attract and retain students in STEM fields.

Our learning experiences come in many forms. We partner faculty with community partners to create 1-2 credit seminar courses that supplement STEM courses. These courses use active learning strategies, namely experiential and project-based learning, to engage students in hands-on, community-based projects. We also develop many student events that enhance STEM courses and help connect students to resources, including undergraduate research opportunities, mentoring, advising, career services, and academic support.

CSIE is demonstrated to have a positive impact on both faculty and students. Students develop a larger interest in research opportunities, and through the relationships they build with our faculty fellows, they have more access to them. Students who take our courses are more likely to enroll or participate in undergraduate research. We offer free STEM textbooks for introductory STEM courses through our Book Loan program. We offer advising and mentoring and can further help students set up appointments with faculty, university advisors and career development centers. Students can learn about their career choices in a STEM field. Community outreach is an integral part of the experiential learning component. Through our course projects, students can develop and offer their solutions to local, community problems. Our courses are 1-2 credit hours and therefore not a large time commitment. CSIE offers a transcript endorsement, or a micro credential, for students to showcase their work. We also offer academic support by way of tutoring.

Figure 1. Titles of Representative Courses Developed for CSIE

\begin{tabular}{|l|}
\hline Current and Previous CSIE Courses \\
\hline Cyanobacteria in the Huron River \\
Meals on Wheels: Routes and Costs \\
Organic and Quantitative Analysis \\
Physics and Engineering \\
Coaching Science Olympiad \\
Statistics for Biological Sciences \\
Algebra Workshop for STEM \\
Scientific Presentation \\
Groundwater Studies \\
Applications in Elementary Math and Physics \\
Digitized Motion Studies \\
Structuring Secure Firewalls \\
Programming for Calculus \\
Special Topics: Duets Scholars \\
Ethics of Genetics \\
Think On Your Feet! \\
Introduction to Physics and Engineering \\
Synthesis and Evaluation of Scientific Literature \\
Water Quality Investigations \\
Scientific Learning \\
\hline
\end{tabular}

\begin{tabular}{|l|}
\hline STEM-IT! Exploring STEM Careers \\
Contaminants in Groundwater \\
Indicator Species in the Huron/Rouge River \\
Modeling Mechanical Systems \\
Statistics for Biology and Earth Science \\
Playpump Hydraulics \\
Math Workshop \\
Algebra and Trig Applications and Workshop \\
Modeling with MATLAB \\
Organic Analysis \\
5 Miles to Clean Water \\
Microbes in Health and Disease \\
Duets Scholars \\
Video Analysis \\
Undiscovered Urban Scientists \\
Physics and Engineering as a Career \\
Water Quality Investigations \\
Water Investigation \\
Surface Water Analysis \\
Understanding Life in the Universe \\
\hline
\end{tabular}


CSIE has impacted students in a meaningful and significant way. To date, over 40 courses (Tratras Contis 2014) have been developed and one-third have been regularized (offered consecutive semesters). Depicted in Figure 1 are a sampling of courses with our community partners and federal support. There is a large degree of course diversity. Many courses are CUREs (course-based undergraduate research experience) that offer exploratory research. Other courses are metacognitive in nature where students are taught how to think, study from a disciplinary sense. All courses are project-based and hands-on.

For example, Cyanobacteria in the Huron River (located near the University Campus) is CSIE's first developed and longest running course. It is an interdisciplinary course developed between Biology and Chemistry faculty, and our community partner, the Huron River Watershed Council. Students are given first-hand exposure to significant environmental issues in the Great Lakes region. They perform exploratory research by sampling water from local rivers and lakes to the test the level of cyanobacteria and other potentially hazardous materials. The data generated by the students are shared with the Huron River Watershed Council and other agencies that monitor and generate reports for lawmakers.

The Cyanobacteria course is an example of engaged and culturally responsive coursework that applies concepts from Biology and Chemistry in a real-world setting by analyzing water samples from our immediate environment. Toxic cyanobacteria present a local, serious problem and our approach allows students to develop a deeper awareness and unique skills to investigate, confront and communicate on these issues.

\section{Results}

Student data was collected retrospectively from the Office of Institutional Research to determine CSIE impact on student success rates. Student success is measured by graduation time and retention of STEM majors. A retrospective study was completed comparing Biology and Chemistry majors enrolled in CSIE courses, against those not enrolled in CSIE courses over a 13-year period. Demographic data was also collected retrospectively and measured to determine growth/decline of student groups enrolled in CSIE courses, and graduation.

\section{CSIE: Successful STEM Education Intervention}

Established in 2005, CSIE specializes in creating learning experiences for students in STEM fields through high impact practices, including Academic Service-Learning (ASL) and experiential learning approaches. ASL is an innovative teaching and learning practice that connects meaningful, communitybased projects to course content and instruction with the intent of enhanced student and civic learning. Experiential learning is a complex active learning strategy that immerses students in a setting and encourages reflection for conceptual and skill development. 
Figure 2. CSIE Logic Model
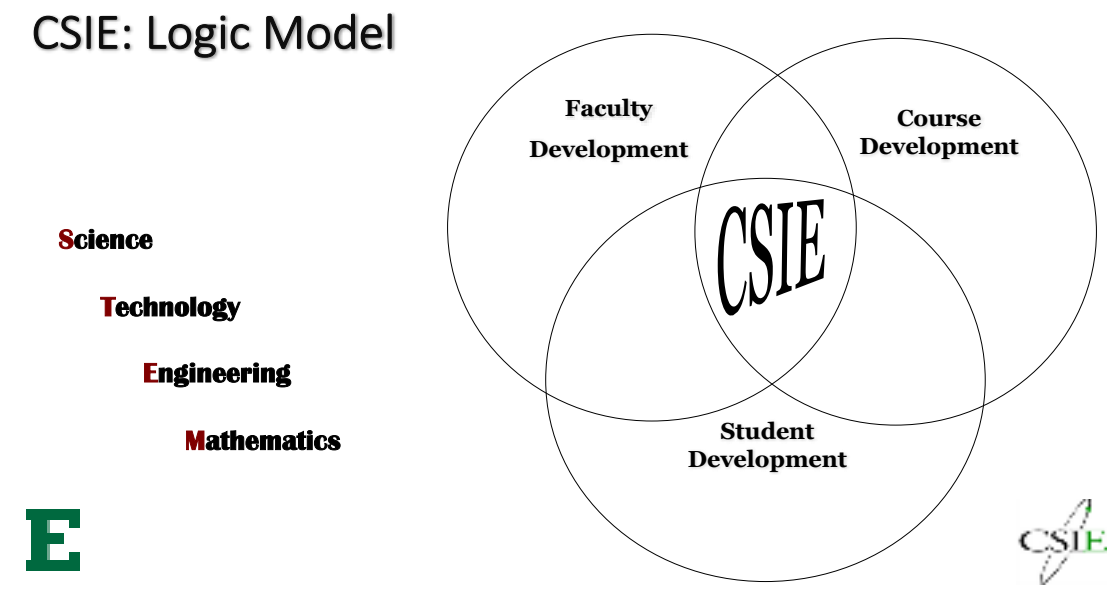

The CSIE logic model intersects among three key components: faculty development, course development, and student development as seen in Figure 2. The CSIE model represents a powerful combination of both ASL and experiential learning by encouraging interdisciplinarity and collaboration between STEM faculty of different disciplines through course development workshops. Faculty focus on identifying courses for integration, common themes, and community and/or industry partners for learning experiences.

These following statistics demonstrate CSIEs positive impact on the EMU community.

Overall, we have seen an increase in enrollment of $6 \%$ over the last five years (beginning of the Department of Education Grant) while the university has seen an overall decrease in course enrollment of $3 \%$. Some of our highest gains have been among underserved groups. We have an $18 \%$ increase in female enrollment. We have demonstrated a $28 \%$ increase in enrollment among African Americans (Females, 37\%; Males, 14\%). We continue to maintain an ongoing community connection by making and maintaining community partnerships for course development and student events. We have set ourselves up to become a "one-stop shop" resource for STEM students. Our office and website contain resources and information about STEM departments, centralized in one location for students, faculty, and staff.

\section{Meaningful Student Engagement}

In working towards creating an inclusive STEM community fostered meaningful student engagement, mutual respect, and trust, CSIE established a diverse platform of learning experiences that includes courses, student events, and academic support. The multitude of platforms attracted and engaged students with varying degrees of interest in STEM fields. Figure 3a depicts the types and variety of learning experiences offered through the CSIE program that reflect the contact hours students can engage with CSIE faculty and staff. Students can engage in 
CSIE activities through course credit hours, CSIE office hours (services include mentoring, advising, tutoring, and other services), and informal student events.

Figure 3. CSIE Creates Meaningful Student Engagement (a) CSIE Meaningfully Engages Students through Academic Support, Seminar Courses and Student Events, Reflected by the Amount of Contact Hours Students can Engage with Faculty (b) Increased Enrollment in CSIE Courses Compared to University Enrollment (c) Types of Undergraduate Seminar Courses Developed by CSIE Program

a

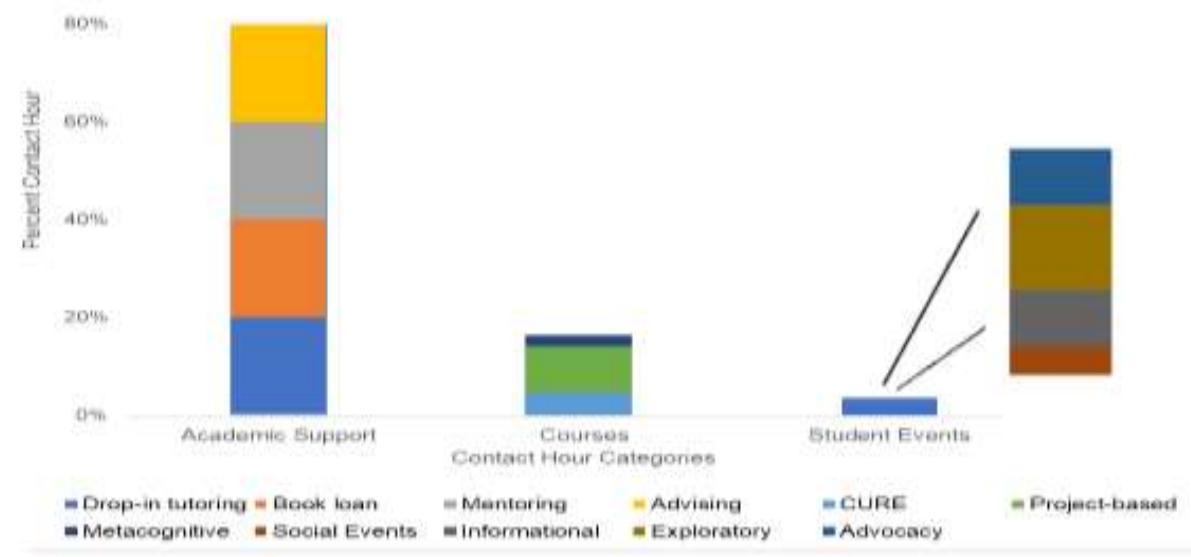

b

$\circ$
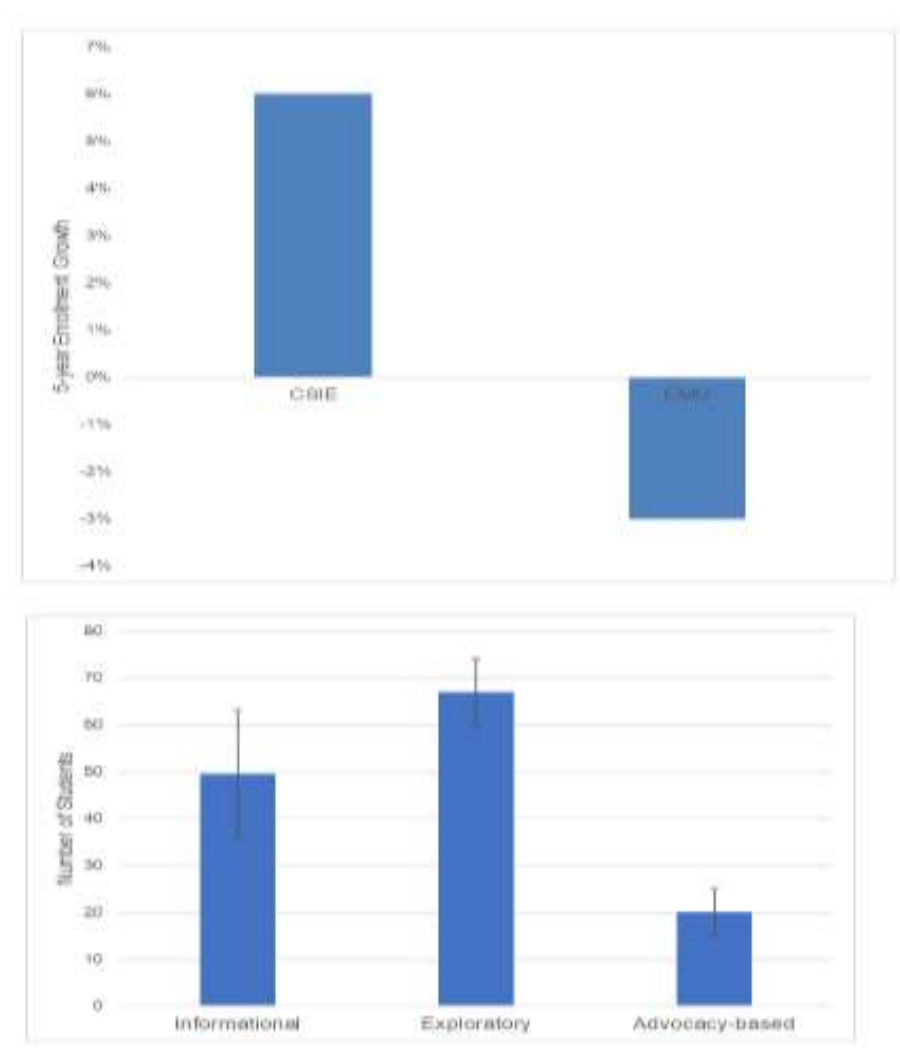
Most courses are exploratory, offering course-based undergraduate research experiences, and project-based learning. Other courses offered are informational, engaging students in career development, and advocacy-based, teaching students, critical agency and metacognitive learning.

Our combined efforts through formal and informal formats represent our ongoing relations with the campus and external communities. Our data indicate that students continue to participate in all activities, especially 1-2 credit hour seminar courses (Figure 3b) as our enrollment has steadily increased even as enrollment at Eastern Michigan University has declined. A variety of high impact practices (HIP) are used to engage students in CSIE courses, including coursebased undergraduate research experiences (CUREs), project-based learning, metacognition, career development, and culturally relevant learning (Figure 3c). Altogether, these data indicate that CSIE creates an inclusive STEM community that continues to attract students through culturally relevant and engaging course work, informal and academic support.

This large increase is due to incorporating research experiences in introductory stem courses, as well as incorporating active learning strategies in the curriculum.

Course-based undergraduate research experiences increase participation of first generation and underrepresented students in STEM.

Figure 4. Samples of Posters and Fliers of Student Engagement Activities

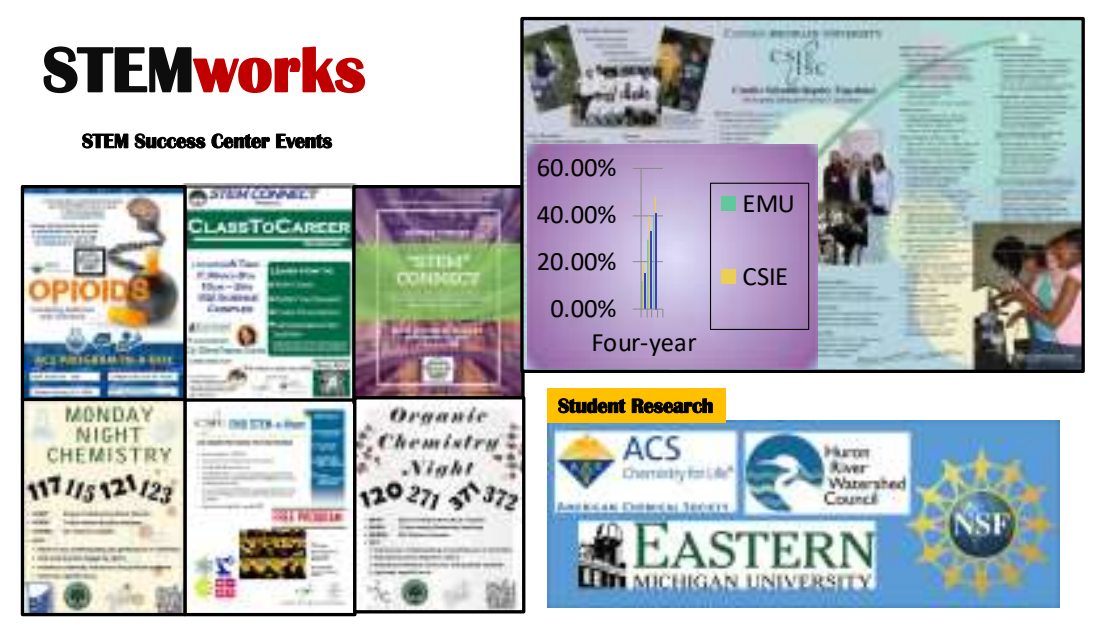

Figure 4 shows examples of posters and fliers that promote and advertise some of the outreach events sponsored by CSIE. They include webinars (Opioids), Class to Career workshops, chemistry tutoring sessions and math summer bridge programs (STEM-a-Thon), solvathon (SolvEMU), professional presentations at regional and national STEM meetings, and partnerships with our local agencies. 


\section{CSIE Increased Impact on Student Success}

Enriched learning experiences have positive impacts on student success rates, including academic years before graduation, STEM retention and increased participation among underserved students. CSIE courses have positively impacted student graduation rates. As shown in Table 1, 53\% of CSIE students graduate within four years, compared to $45 \%$ of EMU students. Among STEM majors, more students who majored in a STEM field and enrolled in a CSIE course graduated than non-CSIE STEM majors, 54\% to 51\%, respectively. Finally, 78\% of students enrolled in a CSIE course during their first two years graduated from EMU within 4 years, as compared to $45 \%$ of EMU students not enrolled in a CSIE course.

CSIE has also positively impacted STEM retainment. Student data indicate that more students enrolled in a CSIE courses graduated with a STEM major, as compared with non-CSIE STEM majors, $63 \%$ to $58 \%$ respectively (Table 1). An analysis on next in progression enrollment, indicating continuation of STEM coursework supports this finding (Table 1). A larger number of students enrolled in introductory Biology and Chemistry concurrently in a CSIE course continued with subsequent coursework when compared to non-CSIE university students: introductory Biology (CSIE 66\%; non-CSIE 49\%) and introductory Chemistry courses (CSIE 71\%; non-CSIE 21\%). Overall, the combination of faster graduation time and increased STEM retention of STEM majors and STEM coursework demonstrate the efficacy of the CSIE platform to increase student success.

Table 1. Student Success Statistics, Demonstrated by Time to Graduation, Retention of STEM Majors, and Retention in STEM Courses

\begin{tabular}{|l|c|c|}
\hline CSIE Increases Student Success Rate & CSIE & EMU \\
\hline Graduation within 4 years & $53 \%$ & $45 \%$ \\
\hline Graduation within 4 Years among STEM Majors & $54 \%$ & $51 \%$ \\
\hline STEM Graduates & $63 \%$ & $58 \%$ \\
\hline Next in Progression Enrollment & & \\
\hline Biology Enrollment & $66 \%$ & $49 \%$ \\
\hline Chemistry Enrollment & $71 \%$ & $21 \%$ \\
\hline
\end{tabular}

Students who take our courses graduate faster than non-CSIE students. As such, $78 \%$ of students enrolled in a CSIE course during their first two years graduate within 4 years, as compared to $45 \%$ of non-CSIE students who graduate in 4 years. The CSIE model is successful at recruiting and retaining STEM majors. A survey of CSIE student majors has shown that we retained $61 \%$ of STEM majors and recruited $21 \%$ of non-STEM majors.

CSIE is also successful in course retainment through a measure called "next in progression courses". For example, "Biology 1" is followed by "Biology 2", with "Biology 2" being the next in progression course. Students enrolled in CSIE courses are more likely to enroll in next in progression courses. In Biology, 66\% of CSIE students compared to $49 \%$ non-CSIE enrolled in the next course progression; in Chemistry, $71 \%$ of students enrolled in a CSIE course enrolled in 
the next course progression, as compared with $21 \%$ of non-CSIE chemistry students.

Many CSIE students continue the research track. Finally, a post-graduate survey found that $62 \%$ of CSIE students work in a STEM profession. $47 \%$ went on to complete a post-graduate degree, compared to $36 \%$ of EMU students.

\section{Broadening Participation}

Broadening participation in STEM by promoting diversity and inclusion is a central goal of national STEM education reform. The combination of high impact practice through courses, student events, and academic and social support enabled the CSIE model to broaden participation among underserved student groups. Table 2 demonstrates enrollment demographics over five-year time period, indicating $18 \%$ growth in female enrollment. Additionally, enrollment grew among African Americans by $28 \%$, specifically $37 \%$ growth among African American females and $14 \%$ increase among African American males.

Table 2. STEM Majors among Underserved Students - CSIE STEM Graduates Greater Numbers of Underserved Students

\begin{tabular}{|c|c|c|c|c|c|c|c|c|c|c|c|c|c|}
\hline & & \multicolumn{2}{|c|}{$2007 / 08$} & \multicolumn{2}{|c|}{$2008 / 09$} & \multicolumn{2}{|c|}{$2009 / 10$} & \multicolumn{2}{|c|}{$2010 / 11$} & \multicolumn{2}{|c|}{$2011 / 12$} & \multicolumn{2}{|c|}{$2012 / 13$} \\
\hline & & CSIE & EMU & CSIE & EMU & CSIE & EMU & CSIE & EMU & CSIE & EMU & CSIE & EMU \\
\hline Male & $\begin{array}{l}\text { Underserved } \\
\text { White }\end{array}$ & $0 \%$ & $17 \%$ & $22 \%$ & $13 \%$ & $10 \%$ & $11 \%$ & $20 \%$ & $15 \%$ & $13 \%$ & $6 \%$ & $25 \%$ & $16 \%$ \\
\hline Male & $\begin{array}{l}\text { Underserved } \\
\text { White }\end{array}$ & $100 \%$ & $83 \%$ & $56 \%$ & $80 \%$ & $90 \%$ & $77 \%$ & $67 \%$ & $78 \%$ & $81 \%$ & $85 \%$ & $67 \%$ & $74 \%$ \\
\hline Female & $\begin{array}{l}\text { Underserved } \\
\text { White }\end{array}$ & $0 \%$ & $20 \%$ & $20 \%$ & $33 \%$ & $22 \%$ & $29 \%$ & $31 \%$ & $9 \%$ & $13 \%$ & $20 \%$ & $38 \%$ & $20 \%$ \\
\hline Female & $\begin{array}{l}\text { Underserved } \\
\text { White }\end{array}$ & $100 \%$ & $60 \%$ & $70 \%$ & $44 \%$ & $44 \%$ & $62 \%$ & $62 \%$ & $82 \%$ & $73 \%$ & $73 \%$ & $62 \%$ & $80 \%$ \\
\hline & & \multicolumn{2}{|c|}{$2013 / 14$} & \multicolumn{2}{|c|}{$2014 / 15$} & \multicolumn{2}{|c|}{$2015 / 16$} & \multicolumn{2}{|c|}{$2016 / 17$} & \multicolumn{2}{|c|}{$2017 / 18$} & \multicolumn{2}{|c|}{$2018 / 19$} \\
\hline & & CSIE & EMU & CSIE & EMU & CSIE & EMU & CSIE & EMU & CSIE & EMU & CSIE & EMU \\
\hline Male & $\begin{array}{l}\text { Underserved } \\
\text { White }\end{array}$ & $11 \%$ & $11 \%$ & $20 \%$ & $25 \%$ & $29 \%$ & $0 \%$ & $27 \%$ & $10 \%$ & $7 \%$ & $11 \%$ & $24 \%$ & $0 \%$ \\
\hline Male & $\begin{array}{l}\text { Underserved } \\
\text { White }\end{array}$ & $79 \%$ & $75 \%$ & $60 \%$ & $70 \%$ & $64 \%$ & $100 \%$ & $64 \%$ & $80 \%$ & $86 \%$ & $78 \%$ & $65 \%$ & $100 \%$ \\
\hline Female & $\begin{array}{l}\text { Underserved } \\
\text { White }\end{array}$ & $11 \%$ & $35 \%$ & $16 \%$ & $29 \%$ & $29 \%$ & $29 \%$ & $50 \%$ & $40 \%$ & $29 \%$ & $42 \%$ & $28 \%$ & $0 \%$ \\
\hline Female & $\begin{array}{l}\text { Underserved } \\
\text { White }\end{array}$ & $78 \%$ & $57 \%$ & $72 \%$ & $57 \%$ & $71 \%$ & $71 \%$ & $50 \%$ & $40 \%$ & $53 \%$ & $42 \%$ & $67 \%$ & $100 \%$ \\
\hline
\end{tabular}

These increases in enrollments translated into an increased number of graduates. Over a 12-year time period, CSIE female graduates outnumbered nonCSIE university graduates, $55 \%$ to $48 \%$, respectively. Furthermore, when gender, race, and major were considered, the CSIE program graduated more underserved students in STEM fields. Specifically, CSIE STEM graduates consistently numbered significantly greater numbers of underserved students, both male and female (Table 2).

\section{CSIE Sustainability}

CSIE is currently being adopted at the institutional level to be sustained beyond grant project completion. To sustain CSIE's presence on campus, many initiatives have been completed. First, it is necessary to secure support from each 
of the STEM departments. Due to the faculty-driven nature of the CSIE program, continued support and commitment from our faculty members and departments is crucial to continue course development. Second, commitments from faculty development centers for the continuation of course development is crucial in maintaining exciting and culturally relevant coursework. Third, it is necessary to continue to develop and cultivate external partnerships with non-governmental agencies (NGOs), government, and industry. Fourth, recognition of student work through transcript recognition allows students to showcase their experiences to employers. The connection to employers affirms our significance on campus and within the greater community. Finally, the CSIE program has established a STEM Center and active learning sites. The CSIE office functions as a STEM center that connects students to resources on campus, while active learning classrooms are available for CSIE faculty fellows to teach CSIE courses throughout the year.

\section{Conclusions}

Enacting deep and meaningful institutional-level and faculty-level change for a more cohesive and inclusive STEM learning culture is difficult. It is even more difficult to scale successful programs to secondary sites, as success stories are limited to primary sites and expansion efforts often fail. The reasons behind the failure to scale are many: inadequate resources; unaligned goals among administration and faculty; insufficient institutional support; lack of ownership in change initiatives; and improper communication channels. Few undergraduate STEM programs have been successful at scaling to secondary sites, consisting of interventions that are: low-cost, not complex, adaptable, and aligned goals among stakeholders.

EMU believes that the CSIE program is an established part of the STEM culture at EMU. It will continue to grow as a critical mass of STEM faculty (about $50 \%$ ) continue to include community-based research experiences in introductory STEM courses, as well as incorporating active learning strategies in the curriculum; and to work collaboratively between departments and with our community partners. We also know that course-based undergraduate research experiences increase participation of first generation and underrepresented students in STEM.

It is hoped that the program expands to all STEM departments and that this model is replicated at other similar institutions.

\section{Acknowledgments}

We wish to thank the following United States federal granting agencies for their support to develop and implement the CSIE program over the past 15 years. Our first developmental work was funded by the National Science Foundation STEP Type I Program (\#0525514). The institutionalization grant was funded through the US Department of Education Title III SIP Program (\#P031A140166). Additional funding was awarded for developing and implementing two significant 
outreach events, STEM-A-Thon and SolvEMU through grants from the Women in Philanthropy at EMU.

We would like to thank EMU for providing office space for the program and the US Department of Education for funding an active-learning project-based lab in the newly renovated Strong Science Hall on EMU's campus. In addition, our heartfelt thanks go to all the students, CSIE Faculty Fellows, our STEM Adviser, and our community partners who continue to collaboratively work to provide our students with innovative, experiential learning opportunities in STEM.

We also want to thank our many staff members, undergraduate, and graduate students for their many hours of creative input into making the program successful. Specifically, our CSIE managers over the years, Anne Seaman, Jace Lisi, Sandra Becker and Batoul Abdallah, who have overseen the day to day operations of CSIE and who have built the program successfully. In addition, we thank our many undergraduate and graduate students who have worked with such enthusiasm and competence over the years, including those in the past few years, Omid Hajihassani, Swetha Sadineni, Sai Priya Marrapu, Leon Bryce and Mariah Brito. With these dedicated students, who not only worked in the program, but also advised, tutored and mentored our STEM students, we have been able to build a robust and energized CSIE.

\section{References}

Ashcroft J, Blatti, J, Jaramillo, V (2020) Early career undergraduate research as a meaningful academic experience in which students develop professional workforce skills: a community college perspective. In KY Neiles, PS Kelly, J Fair (eds.), Integrating Professional Skills into Undergraduate Chemistry Curricula. American Chemical Society.

Caniglia J, Tratras Contis E (2013) Travelling salesman solves a "meals on wheels" problem: utilizing academic service-learning in an algebra/computer science course. In V Akis (ed.), Essays on Mathematics and Statistics: Volume 3. Athens, Greece: ATINER.

Estrada, M, Burnett, M, Campbell AG, Campbell PB, Denetclaw WF, Gutiérrez CG, et al. (2016) Improving underrepresented minority student persistence in STEM. CBE-Life Sciences Education 15(3): es5.

Kendricks, K, Arment, A, Nedunuri KV, Lowell CA (2019) Aligning best practices in student success and career preparedness: an exploratory study to establish pathways to stem careers for undergraduate minority students. Journal of Research in Technical Careers 3(1): 27-48.

King M, Marshall A, Zaharchuk D (2015) Pursuit of relevance: how higher education remains viable in a dynamic world. Executive Report. New York: IBM Corporation.

Mailloux LO, Grimaila M (2018) Advancing cybersecurity: the growing need for a cyberresiliency workforce. IT Professional 20(3): 23-30.

Meyers C, Jones TB (1993) Promoting active learning: strategies for the college classroom. San Francisco: Jossey-Bass Inc.

Syed M, Zurbriggen E, Chemers MM, Goza BK, Bearman S, Crosby FJ, et al. (2019) The role of self-efficacy and identity in mediating effects of stem support experiences. Analyses of Social Issues and Public Policy (19)1: 7-49. 
Theobald, E, Hill, M, Tran E, Agrawal S, Arroyo EN, Behling S, et al. (2020) Active learning narrows achievement gaps for underrepresetned students in undergraduate scince, technology, engineering, and math. Proceedings of the National Academy of Sciences of the United States of America - PNAS 117(12): 6476-6483.

Tratras Contis E (2014) Advancing science, engaging STEM learners. The International Journal of Science, Mathematics and Technology Learning 20(4): 81-89.

Xue Y, Larson RC (2015) STEM crisis or STEM surplus? Yes and yes. Monthly Labor Review 138(5). 
